\title{
Efficacy Comparison of Tenofovir and Entecavir in HBeAg-Positive Chronic Hepatitis B Patients with High HBV DNA
}

\author{
Hong Shi, ${ }^{1}$ Mingxing Huang, ${ }^{2}$ Guoli Lin, ${ }^{1}$ Xiangyong Li, ${ }^{1}$ Yuankai Wu, ${ }^{1}$ \\ Yusheng Jie, ${ }^{1}$ and Yutian Chong ${ }^{1}$ \\ ${ }^{1}$ Department of Infectious Disease, Third Affiliated Hospital of Sun Yat-sen University, Guangzhou 510630, China \\ ${ }^{2}$ Department of Infectious Disease, Fifth Affiliated Hospital of Sun Yat-sen University, Zhuhai 519000, China
}

Correspondence should be addressed to Yutian Chong; chongyutian2013@126.com

Received 30 November 2015; Revised 22 January 2016; Accepted 7 February 2016

Academic Editor: Fumio Imazeki

Copyright (c) 2016 Hong Shi et al. This is an open access article distributed under the Creative Commons Attribution License, which permits unrestricted use, distribution, and reproduction in any medium, provided the original work is properly cited.

Objectives. To compare entecavir (ETV) and tenofovir disoproxil fumarate (TDF) effects in chronic hepatitis B (CHB) patients with high HBV DNA. Method. 96 patients treated initially with tenofovir (TDF group) or entecavir (ETV group) were included in this retrospective study. The following parameters were assessed: $\mathrm{HBeAg}$ and hepatitis B e antibody (anti-HBe) status, serum alanine aminotransferase (ALT), and HBV-DNA levels at weeks 4, 12, 24, 36, 48, 60, 72, and 96; time to ALT normalization, undetectable HBV-DNA levels, and HBeAg seroconversion; total duration of follow-up and adverse reactions. Results. The patients included 66 (69\%) and 30 (31\%) individuals administered ETV and TDF, respectively, comprising $75 \%$ males. They were $35.1 \pm 4.5$ and $33.7 \pm 4.6$ years old in ETV and TDF groups, respectively. At 36 weeks, the response rate was significantly higher in the TDF group than in ETV treated patients $(90 \%$ versus $69.7 \%, p=0.03)$. At 48 weeks, less patients administered ETV showed undetectable HBV-DNA levels compared with the TDF group (86.4\% versus $96.7 \%)$, a non-statistically significant difference $(p=0.13)$. Only 1 ETV treated patient developed virological breakthrough at 48-96 w. No adverse reactions were found. Conclusion. ETV and TDF are comparable in efficacy and safety to suppress HBV-DNA replication in HBeAg-positive CHB patients with high HBV DNA.

\section{Introduction}

Chronic hepatitis B virus (HBV) infection is a significant health problem worldwide; it may cause serious complications such as cirrhosis, liver failure, and hepatocellular carcinoma (HCC) [1]. In China, although HBV prevalence was reduced to $7.2 \%$ in the general population by 2006,97 million people are HBV carriers, with at least 20 million still suffering from active chronic $\mathrm{HBV}$ infection, alone or in combination with cirrhosis and/or HCC [2]. Early diagnosis and treatment of chronic hepatitis $\mathrm{B}(\mathrm{CHB})$ infection is crucial for reducing morbidity and mortality.

The primary goal of CHB treatment is to reduce the risk of developing chronic liver disease and associated complications. Two different treatment strategies are commonly used for patients with $\mathrm{CHB}$ infection: therapy of fixed duration with immunomodulators such as standard or PEGylated interferon- $\alpha$, long-term treatment with the nucleos $(\mathrm{t})$ ide analogues lamivudine (LAM), adefovir dipivoxil (ADV), entecavir (ETV), telbivudine (LdT), or tenofovir (TDF). Rates of resistance to LAM and ADV have been reported to be $65-70 \%$ and $18-29 \%$, respectively, after $4-5$ years of treatment $[3,4]$. LdT results in 5-25\% resistance in HBeAgpositive patients, with $2.3-11 \%$ resistance obtained in $\mathrm{HBeAg}$ negative patients [5]. ETV and TDF are recommended firstline therapeutics for $\mathrm{CHB}$ in current guidelines thanks to their high potency in viral suppression, providing also genetic barriers against resistance [6-8].

A few studies have compared the efficacy of ETV and TDF. For instance, we previously demonstrated that TDF and ETV both rapidly inhibit HBV DNA replication in naïve $\mathrm{CHB}$ patients [9]. However, data concerning $\mathrm{CHB}$ patients with high HBV-DNA are limited. The aim of the current study was to investigate the effects of ETV and TDF in HBeAg-positive $\mathrm{CHB}$ patients with high $\mathrm{HBV}$ DNA. 
TABLE 1: Baseline characteristics of patients administered tenofovir (TDF) or entecavir (ETV).

\begin{tabular}{|c|c|c|c|}
\hline & $\operatorname{ETV}(n=66)$ & $\operatorname{TDF}(n=30)$ & $p$ \\
\hline Age, years & $35.1 \pm 4.5$ & $33.7 \pm 4.6$ & 0.28 \\
\hline Gender, male & $74.2 \%(49 / 66)$ & $76.7 \%(23 / 30)$ & 1.00 \\
\hline Height $(\mathrm{cm})$ & $167.09 \pm 7.22$ & $164.93 \pm 7.45$ & 0.19 \\
\hline Weight (kg) & $62.58 \pm 10.43$ & $58.37 \pm 7.98$ & 0.05 \\
\hline History of alcohol use & $21.2 \%(14 / 66)$ & $26.7 \%(8 / 30)$ & 0.61 \\
\hline History of smoking & $19.7 \%(13 / 66)$ & $26.7 \%(8 / 30)$ & 0.44 \\
\hline Family history of Hepatitis B & $71.2 \%(47 / 66)$ & $70.0 \%(21 / 30)$ & 1.00 \\
\hline Pretreatment HBV-DNA, $\log _{10} \mathrm{IU} / \mathrm{mL}$ & $7.33 \pm 0.79$ & $7.25 \pm 0.83$ & 0.62 \\
\hline Pretreatment serum ALT, U/L & $154.59 \pm 122.05$ & $168.53 \pm 112.39$ & 0.60 \\
\hline Elevated serum ALT before therapy & $93.9 \%(62 / 66)$ & $96.7 \%(29 / 30)$ & 0.58 \\
\hline
\end{tabular}

$\mathrm{IU} / \mathrm{mL}$, international unit per milliliter; U/L, unit per liter; ALT, alanine aminotransferase.

\section{Materials and Methods}

2.1. Study Design and Data Collection. This was a retrospective cohort study, conducted at the Third Affiliated Hospital of Sun Yat-sen University, from March 2012 to March 2015. A total of $96 \mathrm{HBeAg}$ positive $\mathrm{CHB}$ patients were assessed, including 66 and 30 cases treated orally with entecavir at $0.5 \mathrm{mg} /$ day (ETV group) and tenofovir at $300 \mathrm{mg} /$ day (TDF group). TDF and ETV, both first line therapeutics for HBeAgpositive chronic hepatitis B patients with high HBV DNA, were presented to the subjects for their selection in clinic. The study was approved by the ethics committee of the Third Affiliated Hospital of Sun Yat-sen University.

Inclusion criteria were (1) diagnosis of $\mathrm{CHB}$ with no prior history of treatment for $\mathrm{CHB}$, including TDF and ETV administration; (2) HBeAg seropositivity; (3) pretreatment serum HBV-DNA levels > $10^{6} \mathrm{IU} / \mathrm{mL}$; (4) at least 18 years of age at treatment initiation; (5) treatment for at least one year. Patients were excluded from the study if they (1) were coinfected with HCV, HDV, and/or HIV; (2) had comorbidities with alcoholic, drug-induced, or autoimmune liver diseases.

Parameters such as age, height, weight, serum alanine aminotransferase (ALT) and HBV DNA levels at baseline, gender, alcohol use, smoking status, were recorded for each patient prior to treatment. The following parameters were assessed: HBeAg and anti-HBe status, serum ALT and HBVDNA levels at weeks 4,12, 24, 36, 48, 60, 72, and 96 of treatment; time to ALT normalization, undetectable HBVDNA levels, and HBeAg seroconversion; total duration of follow-up. Independent variables reflecting the virological response to treatment were determined by survival analysis. Cumulative probability of virological response was assessed in patients treated with entecavir and tenofovir, respectively. Compliance with therapy was evaluated.

2.2. Definitions. Complete viral suppression was defined as undetectable serum HBV DNA $(<100 \mathrm{IU} / \mathrm{mL}$, or below the lower limit of quantification of the PCR assay) at week 48. Virological breakthrough was defined as a $>1 \log _{10} \mathrm{IU} / \mathrm{mL}$ increase in serum HBV-DNA levels from nadir in two consecutive measurements.

$\mathrm{ALT} \leq 40 \mathrm{U} / \mathrm{L}$ was considered normal [10].
2.3. Statistical Analyses. The SPSS 13.0 software (SPSS Inc., Chicago, IL, USA) was used for all statistical analyses. Categorical variables were defined as proportion (\%) and compared by Chi-square or Fisher's exact test. Continuous variables are mean \pm standard deviation (SD) and were assessed by Student's $t$-test or Mann-Whitney $U$ test, as appropriate. Cox regression analysis was performed in search of variables determining the virological response. Cumulative rates of complete viral suppression were analyzed by the Kaplan-Meier method. $p<0.05$ was considered statistically significant.

\section{Results}

3.1. Patient Characteristics. A total of 96 patients were included in this study, comprising 66 and 30 cases treated with entecavir (ETV group) and tenofovir (TDF group), respectively. They were $35.1 \pm 4.5$ and $33.7 \pm 4.6$ years old in the ETV and TDF groups, respectively. No statistically significant differences were observed between the ETV and TDF groups patients in age, gender, height, weight, smoking and drinking history, HBV family history, baseline ALT levels, and HBVDNA levels (Table 1).

3.2. ALT Normalization Rates. The fractions of patients with normalized serum ALT levels at weeks 4, 12, 24, 36, 48, and 72 did not differ significantly between the two groups. However, serum ALT levels in ETV treated individuals were significantly lower compared with values obtained for the TDF group at 12 and 24 weeks (Table 2). The KaplanMeier survival analysis showed no statistically significant difference in the normalization rates between the two groups (Figure 1(a)).

3.3. Virological Response. Patients treated with ETV and TDF had high viral response rates at 48 weeks $(86.4 \%$ versus $96.7 \%)$, with a higher value in the TDF group, although the difference was not statistically significant $(p=0.13)$. At $36 \mathrm{w}$, the response rate in the TDF group was significantly higher than that obtained for ETV treated patients $(90 \%$ versus $69.7 \%, p=0.03$ ) (Table 2 ). At $4,12,24$, and 48 weeks HBV-DNA levels were similar between the two groups, with no statistically significant difference (Table 2). 
TABLE 2: Cumulative virological responses in patients with chronic hepatitis B.

\begin{tabular}{lccc}
\hline Undetectable & ETV $(n=66)$ & TDF $(n=30)$ & $p$ \\
\hline HBV-DNA (\%) & $4.8 \%(3 / 66)$ & $0 \%(0 / 30)$ & 0.60 \\
12 weeks & $34.8 \%(23 / 66)$ & $43.3 \%(13 / 30)$ & 0.43 \\
24 weeks & $56.1 \%(37 / 66)$ & $63.3 \%(19 / 30)$ & 0.50 \\
36 weeks & $69.7 \%(46 / 66)$ & $90 \%(27 / 30)$ & 0.03 \\
48 weeks & $86.4 \%(57 / 66)$ & $96.7 \%(29 / 30)$ & 0.13 \\
72 weeks & $93.9 \%(62 / 66)$ & $96.7 \%(29 / 30)$ & 0.58 \\
96 weeks & $96.9 \%\left(63 / 65^{*}\right)$ & $96.7 \%(29 / 30)$ & 0.58 \\
\hline
\end{tabular}

TDF, tenofovir; ETV, entecavir; ${ }^{*}$ one patient was excluded because of adding adefovir for the virological breakthrough.

The decline of serum HBV DNA from baseline values showed no statistically significant difference between the two groups at any time point (Figure 2). In addition, KaplanMeier survival analysis revealed no significant difference in undetectable HBV-DNA rates between the two treatment groups (Figure 1(b)). Furthermore, Cox regression analysis demonstrated that no baseline parameter was a significant predictor of virological response (Table 3 ).

3.4. HBeAg Seroconversion. After treatment with ETV and TDF, 5/66 (7.6\%) and 4/30 (13.3\%) patients achieved HBeAg seroconversion, respectively $(p=0.60)$, with median times to seroconversion of 60 and 42 weeks, respectively ( $p=0.48$ ), indicating no statistically significant differences in $\mathrm{HBeAg}$ seroconversion rates and times between the two groups. In agreement, Kaplan-Meier analysis indicated no significant difference in HBeAg seroconversion rates between TDF and ETV treated patients (Figure 1(c)).

3.5. Breakthrough and Resistance. No patients in either group developed chemical breakthrough. Only 1 case in the entecavir group developed virological breakthrough at 72 weeks of follow-up. HBV-DNA levels in this patient rebounded to $5.15 \log _{10} \mathrm{IU} / \mathrm{mL}$ from $<100 \mathrm{IU} / \mathrm{mL}$ at 60 weeks. However, resistance test was not performed at that time. Adefovir dipivoxil was administered to the patient, and HBV-DNA was not detected at 96 weeks.

3.6. Safety and Tolerability. The two drugs were well tolerated, with no report of serious clinical adverse reactions. Serum creatinine was not observed in the TDF group.

\section{Discussion}

The main concern in $\mathrm{CHB}$ patients is the disease progressing to decompensated cirrhosis and hepatocellular carcinoma. Circulating serum HBV DNA levels play a central role in disease progression in these patients. Previous large, longterm studies have shown that serum HBV DNA levels are a major risk factor for cirrhosis: the higher the HBV DNA level, the higher the risk of cirrhosis and HCC [11, 12].

The REVEAL-HBV study also supported an approach of maximal and timely suppression of viral replication as
TABLE 3: Cox regression analysis identifying independent variables predictive of virological response.

\begin{tabular}{lcc}
\hline Variables & HR $(95 \% \mathrm{CI})$ & $p$ \\
\hline Gender & $0.522(0.273-0.997)$ & 0.07 \\
Age & $1.005(0.966-1.045)$ & 0.81 \\
Height & $1.018(0.974-1.063)$ & 0.43 \\
Weight & $0.994(0.965-1.024)$ & 0.68 \\
Alcohol history & $1.158(0.677-1.983)$ & 0.59 \\
Smoking history & $0.967(0.558-1.675)$ & 0.90 \\
Family history & $1.739(1.083-2.794)$ & 0.07 \\
ALT baseline (U/L) & $1.000(0.998-1.002)$ & 0.84 \\
HBV DNA baseline $\left(\log _{10} \mathrm{IU} / \mathrm{mL}\right)$ & $0.904(0.699-1.169)$ & 0.44 \\
Therapy with TDF versus ETV & $0.896(0.552-1.457)$ & 0.66 \\
\hline
\end{tabular}

TDF, tenofovir; ETV, entecavir; ALT, alanine aminotransferase; IU/mL, international unit per milliliter; U/L, unit per liter; HR, hazard ratio; CI, confidence interval.

the target of therapeutic management of patients with $\mathrm{CHB}$, which may delay or prevent liver disease progression [13]. The emergence of resistant HBV is related to viral load at the onset of therapy. Previous studies have indicated that patients with high pretreatment serum HBV DNA levels seem to be at a higher risk for developing resistant HBV during long-term LAM or ADV therapy $[14,15]$. Therefore, current guidelines recommend ETV and TDF as first-line nucleoside/nucleotides. These are potent antivirals that effectively suppress HBV DNA replication with high genetic barrier for resistance [6-8].

Phase III clinical trials have shown that ETV and TDF in treatment-naïve patients suppress HBV DNA to undetectable levels by 48 weeks in $67 \%$ and $76 \% \mathrm{HBeAg}$-positive $\mathrm{CHB}$ patients, respectively $[16,17]$. Tenofovir and entecavir have been compared for CHB treatment efficacy and safety, but discrepant data have been reported, probably due to the retrospective design of these studies. Indeed, a multicenter, retrospective study comparing ETV and TDF efficacy for initial treatment of $\mathrm{CHB}$ showed no difference between the two patient groups in viral response [18]. Meanwhile, another trial suggested that TDF yields a better virological response compared with ETV (OR 1.796, $p=0.01$ ) [19]. The present study aimed to compare complete virological response rates between ETV and TDF in the treatment of $\mathrm{HBeAg}$ positive $\mathrm{CHB}$ patients with high viral load. As shown above, no statistically significant differences were obtained in the inhibitory effects of the two drugs.

However, a recent report demonstrated that TDF is superior to ETV in achieving complete viral suppression in HBeAg-positive CHB patients with high HBV DNA among HBeAg-positive patients. There was no significant difference in viral suppression between the two drugs among $\mathrm{HBeAg}$ negative patients [20].

During follow-up, very few $\mathrm{HBeAg}$ negative $\mathrm{CHB}$ patients had high viral load in this study, and were not included in the analyses. Previously reported HBV DNA suppression rates range from $68 \%$ to $90 \%$ and $61 \%$ to $92 \%$ for the TDF and ETV groups, respectively, after 48 weeks of therapy [21-23]. In the present study, TDF had higher 

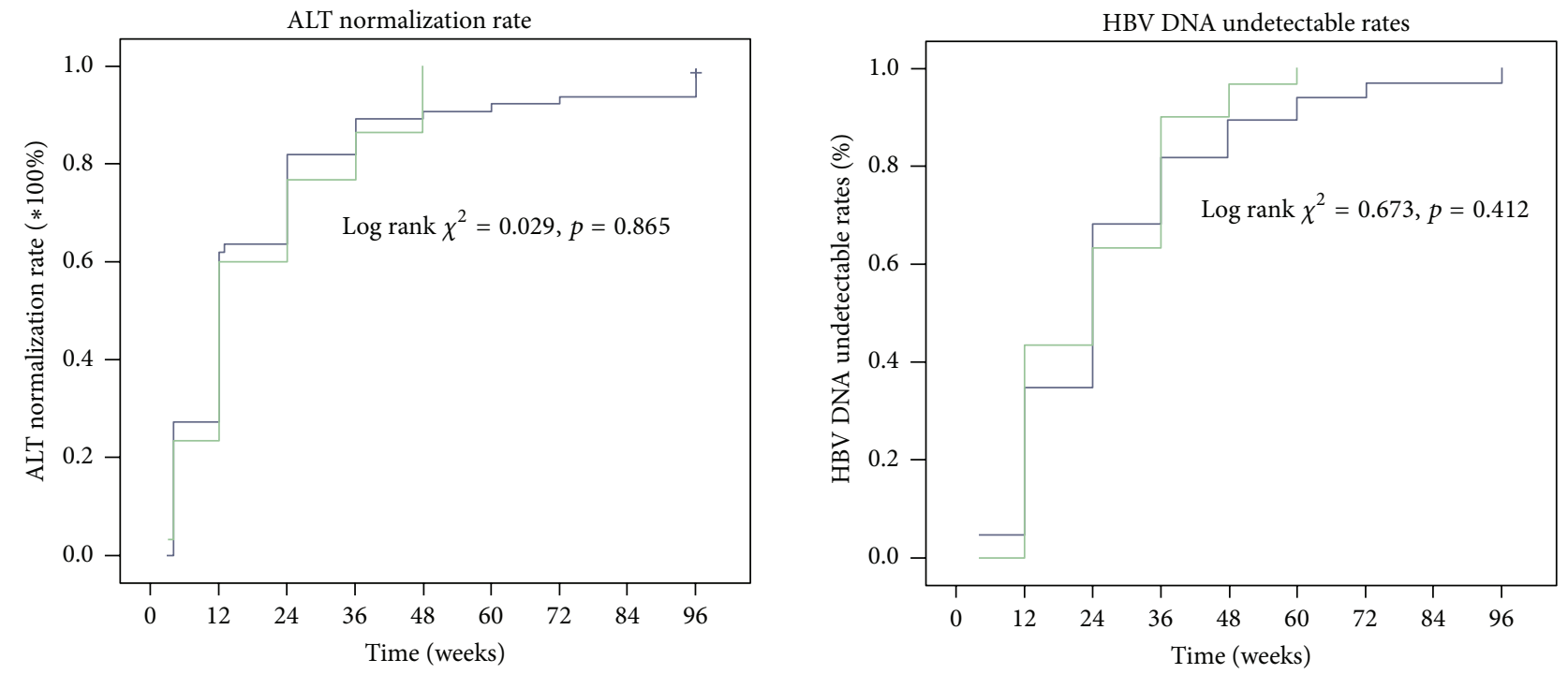

Number Total

$\begin{array}{lllllllllll}\text { ETV } & 62 & 0 & 14 & 39 & 49 & 50 & 51 & 53 & 54 & 57\end{array}$

$\begin{array}{lllllllllll}\text { TDF } & 29 & 0 & 4 & 14 & 19 & 24 & 26 & 26 & 26 & 27\end{array}$

Number Total

$\begin{array}{llllllllllll}\text { ETV } & 66 & 0 & 3 & 23 & 37 & 46 & 57 & 58 & 62 & 62 & 63\end{array}$

$\begin{array}{llllllllllll}\text { TDF } & 30 & 0 & 0 & 13 & 19 & 27 & 29 & 29 & 29 & 29 & 29\end{array}$

Group
$\square$ ETV
$\square$ TDF

+ ETV-censored

Group

$\neg \mathrm{ETV}$

$\neg \mathrm{TDF}$

(a)

(b)

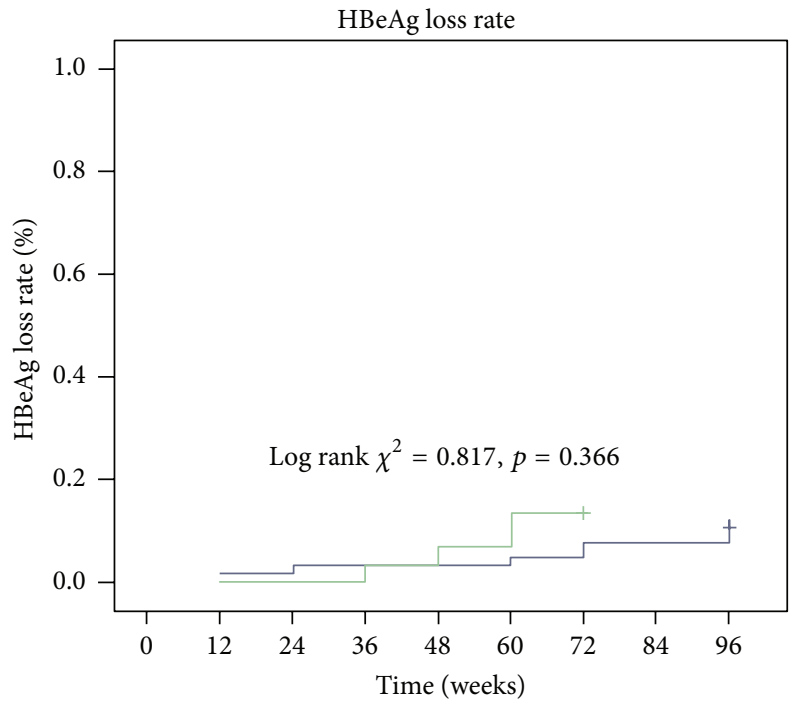

Number Total

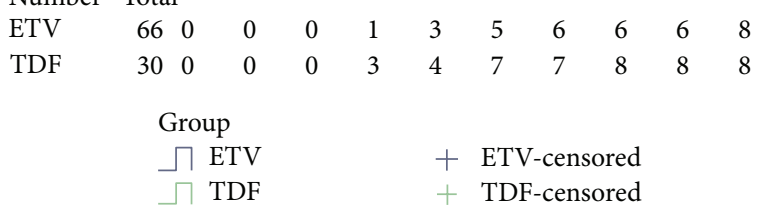

(c)

Figure 1: Kaplan-Meier analyses. (a) Alanine aminotransferase (ALT) normalization rates; (b) HBV undetectable DNA rates; (c) HBeAg seroconversion rates. TDF, tenofovir; ETV, entecavir. 


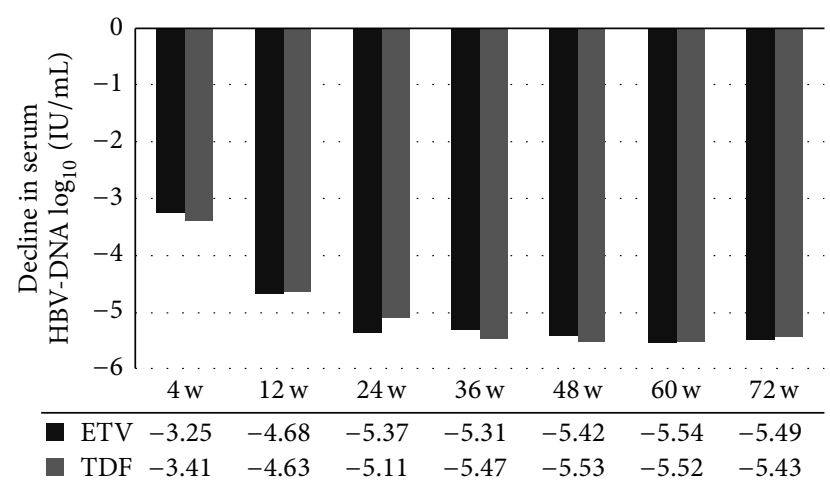

FIGURE 2: Decline of serum HBV DNA levels from baseline values. TDF, tenofovir; ETV, entecavir; IU/mL, international unit per milliliter; w, weeks.

$48 \mathrm{w}$ virological response (96.7\% versus $86.4 \%$ ). However, 72 weeks of treatment with both drugs resulted in higher virological response rates, with $93.9 \%$ and $96.7 \%$ obtained for the ETV and TDF groups, respectively. Interestingly, no significant difference was found in virological response between the ETV and TDF groups (96.9\% versus $96.7 \%)$ at 96 weeks. Moreover, HBV-DNA levels were similar at 4, 12, 24, and 48 weeks between the two groups. These data indicated that the two drugs have similar strengths in inhibiting HBV DNA, in agreement with a recently published meta-analysis assessing 7 studies and showing that ETV and TDF are similar in maintenance HBV DNA inhibition [24].

Serum ALT levels reflect the host immune response to the virus. Virological response is therefore often accompanied by ALT normalization, showing attenuated liver damage. Our study showed that patients in the ETV group had lower serum ALT levels in the early stage of treatment (12 w and $24 \mathrm{w}$ ). However, no significant difference in ALT levels was observed between the two groups at any follow-up point, corroborating previous research [25]. Another measure of efficacy is loss of $\mathrm{HBeAg}$ and development of antibodies to $\mathrm{HBeAg}$ (anti-HBe), referred to as $\mathrm{HBeAg}$ seroconversion, which is associated with low HBV-DNA levels and clinical remission of liver disease in most patients. HBeAg seroconversion is also associated with a sustained reduction in HBV-DNA levels [26]. At the time of 72 weeks, $\mathrm{HBeAg}$ seroconversion rate is $7.6 \%$ for ETV treated patients and $13.3 \%$ for TDF treated patients; these values are lower than previously reported. In a meta-analysis, ETV and TDF treatment for 48 weeks yielded similar $\mathrm{HBeAg}$ seroconversion rates (10\% versus $16 \%)$ [24]. Another meta-analysis also showed that among different nucleoside analogues, $\mathrm{HBeAg}$ seroconversion rates had no significant difference after 1 year of treatment [27]. HBeAg conversion rates after TDF treatment were $18 \%$ and $19 \%$ after 2 and 3 years, respectively [28]; meanwhile, a serological conversion rate of $24 \%$ was obtained after 2 years of treatment with entecavir [29].

As far as safety is concerned, the two drugs showed good tolerability in this study, in agreement with previous reports. The current guidelines suggest monitoring the renal function during TDF therapy [6-8]. In a large four year study assessing safety of TDF for the treatment of HIV infection, 2\% of patients reported increased serum creatinine levels [30].

In a randomized controlled trial of TDF for long-term treatment of $\mathrm{CHB}$, serum creatinine levels remained stable during the 3 -year period, with $<1 \%$ of patients showing a confirmed $0.5 \mathrm{mg} / \mathrm{dL}$ increase in creatinine. In our study, TDF did not cause kidney safety problems [28].

A recent cohort study in Hong Kong assessing nucleoside analogues (NA) in treating $53500 \mathrm{CHB}$ patients with median follow-up of 4.9 years found that NA do not increase the risk for renal and bone events [31]. Ha et al. also suggested that TDF is not an independent predictor of severe kidney damage; however, they recommended monitoring closely the renal function during antiviral therapy, especially in the elderly or patients with impaired renal function [32]. Although more than half of the patients in this work have been previously assessed [9], the two study populations are quite different in that only chronic hepatitis B patients with high HBV DNA were reevaluated here, and our current findings complement the previous conclusion [9].

Because of its retrospective design, our research has limitations. In addition, sample size was small and follow-up time was short. Nevertheless, this study is meaningful, since only few reports directly compare the efficacy and safety of ETV and TDF in CHB patients with high viral load.

\section{Conclusion}

This study indicated that ETV and TDF have comparable efficacy in suppressing HBV-DNA replication and are well tolerated in $\mathrm{HBeAg}$-positive nucleos(t)ide-naïve $\mathrm{CHB}$ patients with high HBV DNA. However, further randomized prospective studies with more patients are needed to confirm these findings.

\section{Conflict of Interests}

The authors declare that there is no conflict of interests regarding the publication of this paper.

\section{Authors' Contribution}

Hong Shi and Mingxing Huang contributed equally and share the first authorship.

\section{References}

[1] M. Safioleas, N. J. Lygidakis, and C. Monti, "Hepatitis B today," Hepato-Gastroenterology, vol. 54, no. 74, pp. 545-548, 2007.

[2] F.-S. Wang, J.-G. Fan, Z. Zhang, B. Gao, and H.-Y. Wang, “The global burden of liver disease: the major impact of China," Hepatology, vol. 60, no. 6, pp. 2099-2108, 2015.

[3] E. B. Keeffe, D. T. Dieterich, S.-H. B. Han et al., "A treatment algorithm for the management of chronic hepatitis B virus infection in the United States: 2008 update," Clinical Gastroenterology and Hepatology, vol. 6, no. 12, pp. 1315-1341, 2008.

[4] S. J. Hadziyannis, N. C. Tassopoulos, E. J. Heathcote et al., "Long-term therapy with adefovir dipivoxil for HBeAg-negative 
chronic hepatitis B for up to 5 years," Gastroenterology, vol. 131, no. 6, pp. 1743-1751, 2006.

[5] Y.-F. Liaw, E. Gane, N. Leung et al., "2-Year GLOBE trial results: telbivudine is superior to lamivudine in patients with chronic hepatitis B," Gastroenterology, vol. 136, no. 2, pp. 486-495, 2009.

[6] A. S. F. Lok and B. J. McMahon, "Chronic hepatitis B: update 2009," Hepatology, vol. 50, no. 3, pp. 661-662, 2009.

[7] Y.-F. Liaw, J.-H. Kao, T. Piratvisuth et al., "Asian-Pacific consensus statement on the management of chronic hepatitis B: a 2012 update," Hepatology International, vol. 6, no. 3, pp. 531-561, 2012.

[8] European Association for the Study of the Liver, "EASL clinical practice guidelines: management of chronic hepatitis B virus infection," Journal of Hepatology, vol. 57, no. 1, pp. 167-185, 2012.

[9] M. Huang, Y. Jie, H. Shi et al., "Comparison of the efficacy of tenofovir disoproxil fumarate and entecavir for initial treatment of patient with chronic hepatitis B in China," International Journal of Clinical and Experimental Medicine, vol. 8, no. 1, pp. 666-673, 2015.

[10] S.-K. Kim, D.-J. Kim, S.-H. Kim et al., "Normal range of alanine aminotransferase concentration is associated with carotid atherosclerosis," Diabetes Research and Clinical Practice, vol. 88, no. 1, pp. 111-116, 2010.

[11] C.-J. Chen, H.-I. Yang, J. Su et al., "Risk of hepatocellular carcinoma across a biological gradient of serum hepatitis B virus DNA Level," The Journal of the American Medical Association, vol. 295, no. 1, pp. 65-73, 2006.

[12] U. H. Iloeje, H.-I. Yang, J. Su, C.-L. Jen, S.-L. You, and C.-J. Chen, "Predicting cirrhosis risk based on the level of circulating hepatitis B viral load," Gastroenterology, vol. 130, no. 3, pp. 678686, 2006.

[13] U. H. Iloeje, H.-I. Yang, and C.-J. Chen, "Natural history of chronic hepatitis B: what exactly has REVEAL Revealed?" Liver International, vol. 32, no. 9, pp. 1333-1341, 2012.

[14] J. Gauthier, E. J. Bourne, M. W. Lutz et al., "Quantitation of hepatitis B viremia and emergence of YMDD variants in patients with chronic hepatitis B treated with lamivudine," The Journal of Infectious Diseases, vol. 180, no. 6, pp. 1757-1762, 1999.

[15] C.-H. Chen, J.-H. Wang, S.-N. Lu et al., "Characteristics of adefovir resistance in patients with or without lamivudineresistant hepatitis B virus treated with adefovir: a 4-year experience," Liver International, vol. 31, no. 2, pp. 206-214, 2011.

[16] T.-T. Chang, R. G. Gish, R. De Man et al., "A comparison of entecavir and lamivudine for $\mathrm{HBeAg}$-positive chronic hepatitis B," The New England Journal of Medicine, vol. 354, no. 10, pp. 1001-1010, 2006.

[17] P. Marcellin, E. J. Heathcote, M. Buti et al., “Tenofovir disoproxil fumarate versus adefovir dipivoxil for chronic hepatitis B," The New England Journal of Medicine, vol. 359, no. 23, pp. 24422455, 2008.

[18] A. Batirel, E. Guclu, F. Arslan et al., "Comparable efficacy of tenofovir versus entecavir and predictors of response in treatment-naïve patients with chronic hepatitis B: a multicenter real-life study," International Journal of Infectious Diseases, vol. 28, pp. e153-e159, 2014.

[19] B. Ceylan, C. Yardimci, M. Fincanci et al., "Comparison of tenofovir and entecavir in patients with chronic HBV infection," European Review for Medical and Pharmacological Sciences, vol. 17, no. 18, pp. 2467-2473, 2013.

[20] L. Gao, H. N. Trinh, J. Li, and M. H. Nguyen, "Tenofovir is superior to entecavir for achieving complete viral suppression in $\mathrm{HBeAg}$-positive chronic hepatitis B patients with high $\mathrm{HBV}$ DNA," Alimentary Pharmacology \& Therapeutics, vol. 39, no. 6, pp. 629-637, 2014.

[21] P. Lampertico, M. Vigano, R. Soffredini et al., "Entecavir monotherapy in 418 nuc-naive patients with chronic hepatitis $B$ from field practice: high efficacy and favorable safety profile over 3 years of treatment," in Hepatology, p. 1043A, WileyBlackwell Commerce Place, Malden, Mass, USA, 2011.

[22] E. Ridruejo, R. Adrover, D. Cocozzella et al., "Effectiveness of entecavir in chronic hepatitis B NUC-naive patients in routine clinical practice," International Journal of Clinical Practice, vol. 65, no. 8, pp. 866-870, 2011.

[23] P. Lampertico, R. Soffredini, M. Viganò et al., "2-Year effectiveness and safety of tenofovir in 302 NUC-naive patients with chronic hepatitis B: a multicenter European study in clinical practive," Hepatology, vol. 54, supplement 1, abstract 1433, 2011.

[24] W. Ke, L. Liu, C. Zhang et al., "Comparison of efficacy and safety of tenofovir and entecavir in chronic hepatitis B virus infection: a systematic review and meta-analysis," PLoS ONE, vol. 9, no. 6, Article ID e98865, 2014.

[25] S. R. Zuo, X. C. Zuo, C. J. Wang et al., "A meta-analysis comparing the efficacy of entecavir and tenofovir for the treatment of chronic hepatitis B infection," The Journal of Clinical Pharmacology, vol. 55, no. 3, pp. 288-297, 2015.

[26] C.-J. Liu, P.-J. Chen, M.-Y. Lai et al., "Viral factors correlate with hepatitis $\mathrm{B}$ e antigen seroconverson in patients with chronic hepatitis B," Liver International, vol. 26, no. 8, pp. 949-955, 2006.

[27] H. Dakin, C. Fidler, and C. Harper, "Mixed treatment comparison meta-analysis evaluating the relative efficacy of nucleos $(\mathrm{t})$ ides for treatment of nucleos $(\mathrm{t})$ ide-naive patients with chronic hepatitis B," Value in Health, vol. 13, no. 8, pp. 934945, 2010.

[28] E. J. Heathcote, P. Marcellin, M. Buti et al., "Three-year efficacy and safety of tenofovir disoproxil fumarate treatment for chronic hepatitis B," Gastroenterology, vol. 140, no. 1, pp. 132143, 2011.

[29] N. Leung, C. Peng, J. Sollano et al., "Entecavir (ETV) results in higher HBV DNA reduction versus adefovir (ADV) in antiviralnaive $\mathrm{HBeAg}(+)$ adults with high HBV DNA: week 96 results (EARLY Study)," Journal of Hepatology, vol. 48, pp. S373-S374, 2008.

[30] M. R. Nelson, C. Katlama, J. S. Montaner et al., "The safety of tenofovir disoproxil fumarate for the treatment of HIV infection in adults: the first 4 years," AIDS, vol. 21, no. 10, pp. 1273-1281, 2007.

[31] G. L. Wong, Y. K. Tse, V. W. Wong, T. C. Yip, K. K. Tsoi, and H. L. Chan, "Long-term safety of oral nucleos(t)ide analogs for patients with chronic hepatitis B: a cohort study of 53,500 subjects," Hepatology, vol. 62, no. 3, pp. 684-693, 2015.

[32] N. B. Ha, K. Ku, N. B. Ha, K. T. Chaung, H. N. Trinh, and M. H. Nguyen, "Renal function in chronic hepatitis B patients treated with tenofovir disoproxil fumarate or entecavir monotherapy: a matched case-cohort study," Journal of Clinical Gastroenterology, vol. 49, no. 10, pp. 873-877, 2015. 


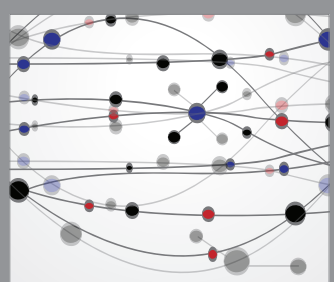

The Scientific World Journal
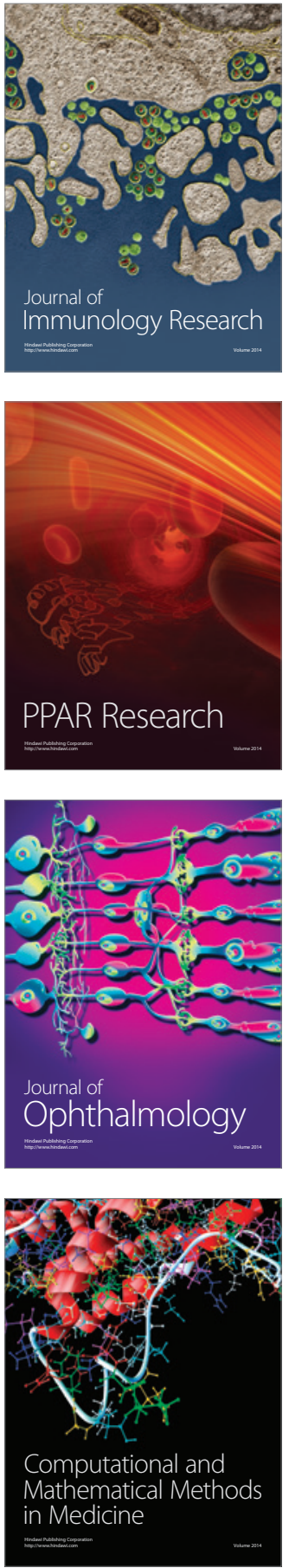

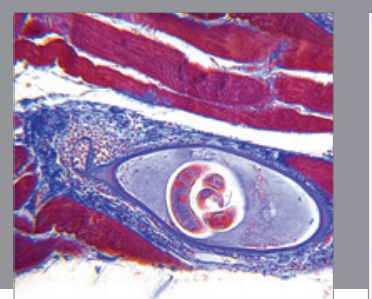

Gastroenterology Research and Practice

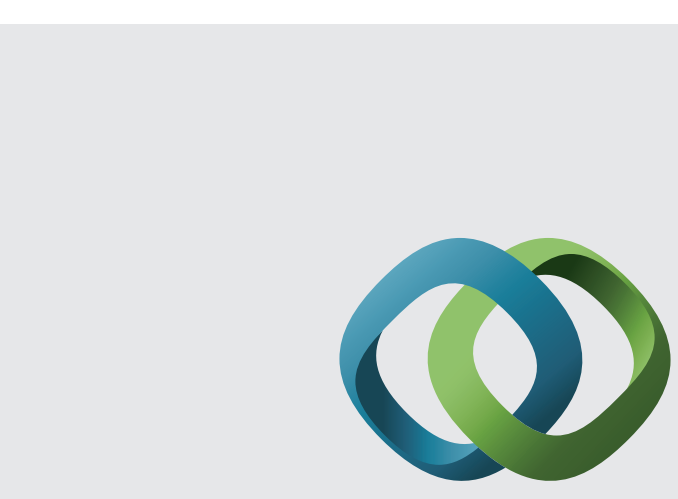

\section{Hindawi}

Submit your manuscripts at

http://www.hindawi.com
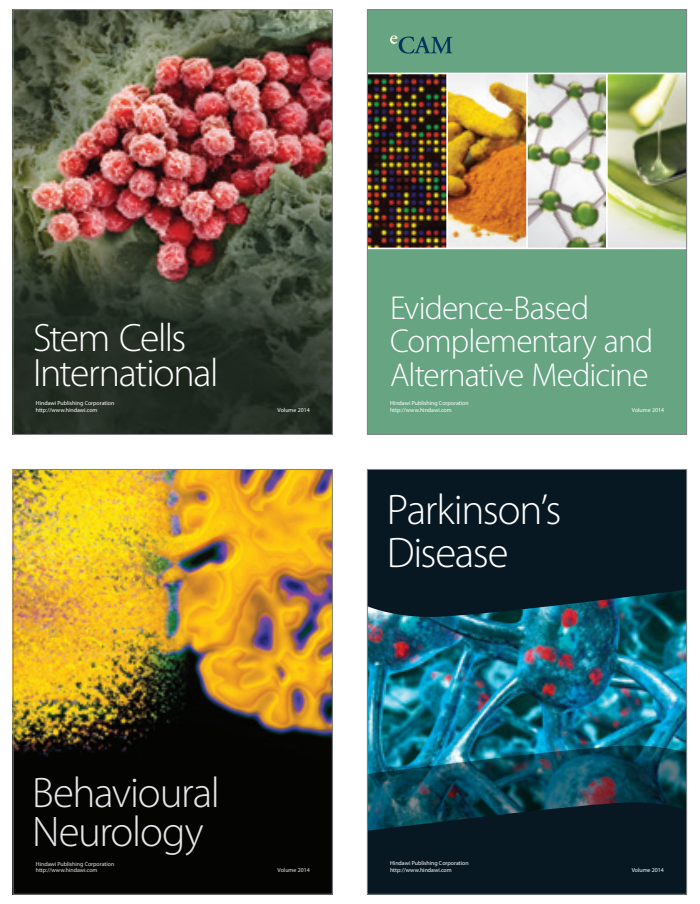
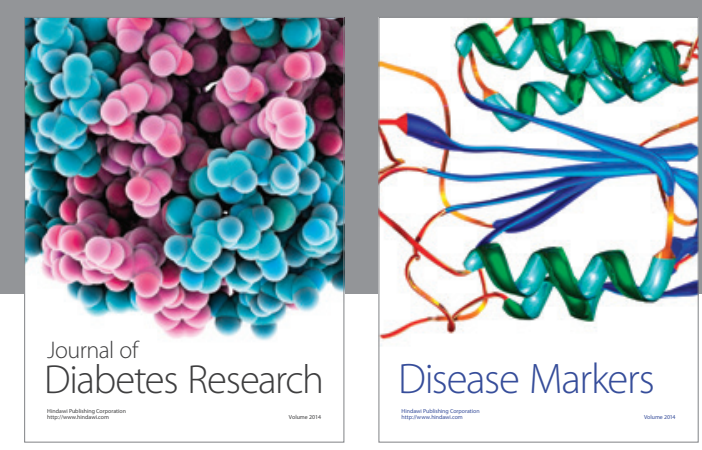

Disease Markers
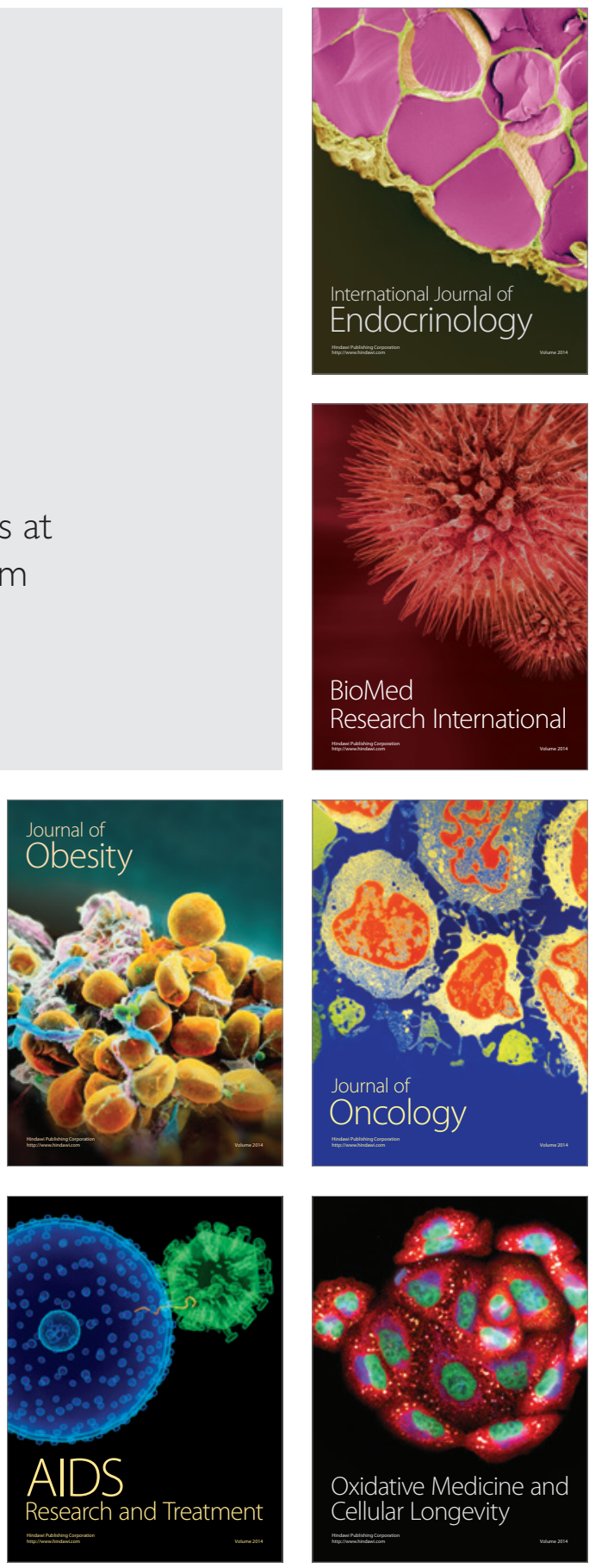